\title{
Protocolo de Prevenção e Tratamento de Infeções Associadas à Terapêutica Imunossupressora de Doenças Autoimunes
}

\section{Guideline for the Prevention and Treatment of Infections Associated with Immunosuppressive Therapy for Autoimmune Diseases}

\author{
Sofia R. VALDOLEIROS ${ }^{1}{ }^{1}$, Isabel FURTADO ${ }^{1}$, Carolina SILVA ${ }^{1}$, Inês CORREIA GONÇALVES ${ }^{1}$, \\ André SANTOS SILVA ${ }^{1,2}$, Olga VASCONCELOS ${ }^{1}$, Ana ABOIM HORTA ${ }^{1,3}$, A. Ludgero VASCONCELOS ${ }^{1}$, Sandra XARÁ ${ }^{1}$, \\ Maria João GONÇALVES ${ }^{1}$, Miguel ARAÚJO ABREU ${ }^{1,4}$, Rui SARMENTO-CASTRO ${ }^{1,4}$ \\ Acta Med Port 2021 Jun;34(6):469-483 - https://doi.org/10.20344/amp.15625
}

\section{RESUMO}

O presente protocolo aborda o risco, prevenção e tratamento da infeção no doente sob terapêutica imunomoduladora ou imunossupressora em contexto de doença autoimune ou autoinflamatória. Subdivide-se nas seguintes secções: fármacos e risco associado de infeção; imunizações; risco, prevenção e tratamento de infeções específicas. Com um número crescente de novos fármacos em utilização nos últimos anos, o tratamento de doenças autoimunes envolve a utilização de terapêuticas imunossupressoras ou imunomoduladoras e associa-se a aumento do risco de infeção, que pode estar presente de uma forma global ou apenas para infeções por agentes específicos, variando amplamente consoante a classe farmacológica e mesmo dentro desta. Na estruturação da estratégia preventiva são fundamentais a caracterização da patologia que motiva a imunossupressão, a compreensão do mecanismo de ação do imunossupressor, a aferição de infeções prévias, o reconhecimento de fatores de risco, a realização de rastreios laboratoriais, a administração de vacinas, a educação do doente e a monitorização de sintomas e sinais clínicos, na dependência de uma gestão clínica necessariamente individualizada.

Palavras-chave: Doenças Autoimunes/terapêutica farmacológica; Doenças Preveníveis por Vacina; Imunossupressores; Infeções/ prevenção \& controlo; Infeções/terapêutica farmacológica

\section{ABSTRACT}

We propose a guideline about the risk, prevention and treatment of infection in the patient under immunomodulatory or immunosuppressive therapy in the context of autoimmune or autoinflammatory disease. It is divided into three sections: drugs and associated risk of infection; immunizations; risk, prevention, and treatment of specific infections. The treatment of autoimmune diseases involves the use of immunosuppressive or immunomodulatory therapies, with an increasing number of new drugs being used. It is associated with an increased risk of infection, which may be present globally or only for specific agents, varying widely depending on the pharmacological class and even within the same class. The prevention strategy and clinical management need to be individually tailored and there are several key factors: characterization of the disease that prompts the immunosuppression, understanding of the mechanism of action of the immunosuppressive drug, knowledge of previous infections, recognition of risk factors, laboratory test results, vaccine administration, monitoring of clinical signs and symptoms and patient education.

Keywords: Autoimmune Diseases/drug therapy; Immunosuppressive Agents; Infections/drug therapy; Infections/prevention \& control; Vaccine-Preventable Diseases

\section{INTRODUÇÃO}

O campo das terapêuticas imunossupressoras ou imunomoduladoras tem crescido exponencialmente, acompanhando o aumento da incidência de patologias como as doenças autoimunes. Embora esta evolução tenha proporcionado grandes avanços no tratamento, o aumento do risco de infeção é uma das principais preocupações associadas. Não obstante o caráter evitável da maioria destas complicações infeciosas, a sua prevenção e gestão constituem um desafio do ponto de vista clínico.

Nos indivíduos com doença autoimune ou autoinflamatória, o risco de infeção depende do mecanismo de ação do fármaco, da natureza e estádio da patologia subjacente, da utilização prévia ou atual de outros imunossupressores, da duração dessas terapêuticas, da exposição cumulativa a estes agentes e das comorbilidades. ${ }^{1}$ Também a imunossenescência contribui para este risco - com a ativação imune contínua produzida pela inflamação crónica, a senescência acelerada das células T é inevitável. ${ }^{1}$ Atendendo à complexidade da avaliação deste risco, é essencial o apuramento de consensos clínicos.

O presente protocolo constitui uma revisão da evidência disponível até à data acerca do risco e gestão da infeção no doente sob terapêutica imunomoduladora ou imunossupressora, pretendendo-se por seu intermédio contribuir

1. Serviço de Doenças Infeciosas. Centro Hospitalar Universitário do Porto. Porto. Portugal.

2. Centro de Diagnóstico Pneumológico de Vila Nova de Gaia. Vila Nova de Gaia. Portugal.

3. Escola de Medicina. Universidade do Minho. Braga. Portugal.

4. Instituto de Ciências Biomédicas Abel Salazar. Universidade do Porto. Porto. Portugal.

$\triangle$ Autor correspondente: Sofia R. Valdoleiros. sofia.valdoleiros@chporto.min-saude.pt

Recebido: 30 de dezembro de 2020 - Aceite: 03 de março de 2021 - First published: 14 de maio de 2021 - Online issue published: 01 de junho de 2021 Copyright @ Ordem dos Médicos 2021 
para a padronização de procedimentos clínicos. Apesar de ser criado no âmbito da consulta especializada do Serviço de Doenças Infeciosas do Centro Hospitalar Universitário do Porto, este documento apresenta aplicação extensível a todas as especialidades médicas que atualmente lidam com estes fármacos, em contexto de doença autoimune ou autoinflamatória.

\section{MATERIAL E MÉTODOS}

A elaboração deste protocolo assentou em revisão bibliográfica por pesquisa na MEDLINE (National Library of Medicine, Bethesda, Estados Unidos da América), com inclusão de publicações na língua portuguesa e inglesa e sem balizamento temporal. Os resumos das características dos medicamentos e os alertas da Agência Europeia do Medicamento (European Medicines Agency - EMA) e da Food and Drug Administration (FDA) foram também analisados.

Subdivide-se nas seguintes secções: fármacos e risco associado de infeção; imunizações; risco e gestão de infeções específicas.

A versão completa deste protocolo, com secções adicionais, pode ser encontrada em Apêndice (ver Apêndice 1: https://www.actamedicaportuguesa.com/revista/index.php/ amp/article/view/15625/Apendice_01.pdf).

\section{IMUNOSSUPRESSORES, IMUNOMODULADORES RISCO ASSOCIADO DE INFEÇÃO}

O potencial de um agente imunossupressor para predispor a complicações infeciosas ou para aumentar o risco de infeção depende principalmente do seu alvo de ação (citocinas, mediadores imunossolúveis, moléculas ou recetores de superfície celular, componentes de cascatas de sinalização intracelular) e consequente impacto no sistema imunológico. Este aumento do risco pode estar presente de uma forma global ou apenas para infeções por agentes específicos, variando amplamente consoante a classe farmacológica e mesmo dentro desta. Embora seja fundamental na estratégia preventiva, em muitos casos, a caracterização exata do efeito destes fármacos no hospedeiro permanece por esclarecer, o que dificulta esta gestão do ponto de vista metodológico e prático.

Os principais fármacos imunomoduladores ou imunossupressores utilizados na terapêutica de doenças autoimunes ou autoinflamatórias encontram-se listados na Tabela 1. A descrição do mecanismo de ação, risco de infeção e recomendações específicas relativamente a cada fármaco pode ser encontrada na versão completa deste protocolo (ver Apêndice 1: https://www.actamedicaportuguesa.com/ revista/index.php/amp/article/view/15625/Apendice_01. pdf).

\section{IMUNIZAÇÕES}

A vacinação, como estratégia de prevenção da infeção, tem um papel essencial em indivíduos imunodeprimidos. Contudo, alguns doentes não são capazes de gerar uma resposta imunológica eficaz à imunização e algumas vaci- nas possuem contraindicações em contexto de imunossupressão (Tabela 2).

Se possível, e nas situações em que a depressão do sistema imunitário é planeada, as vacinas devem ser administradas previamente ao início da imunossupressão: no caso das vacinas inativadas, pelo menos duas semanas antes; no caso das vacinas vivas, pelo menos quatro semanas antes, devendo estas últimas também ser evitadas nas primeiras duas semanas após o início do imunossupressor. $^{2}$

O tempo de duração da imunossupressão varia de acordo com o fármaco (Tabela 3), 3,4 pelo que o timing de administração das vacinas vivas após a suspensão do agente imunomodulador deve ser avaliado individualmente.

\section{Esquemas vacinais e principais indicações}

As principais vacinas administradas em contexto de imunomodulação apresentam-se na Tabela 4. Todos os indivíduos imunodeprimidos devem também ter o Programa Nacional de Vacinação (PNV) atualizado. ${ }^{5}$

\section{Vacinação em contexto de viagem}

Os indivíduos imunocomprometidos, ou que vão iniciar imunossupressão e que vão viajar, devem ter o PNV atualizado para a idade, podendo estar indicada a administração de vacinas extra-PNV.

As vacinas inativadas (contra a encefalite japonesa, encefalite provocada por picada de carraça, febre tifoide, doença meningocócica tetravalente, raiva, poliomielite, cólera e hepatites A e B) podem ser administradas com segurança. $^{2}$

A vacina contra a febre amarela é uma vacina viva e deve ser evitada em indivíduos imunocomprometidos, podendo ser necessário desaconselhar a realização da viagem por esse motivo. ${ }^{2}$ No caso em que a viagem a uma área endémica de febre amarela não possa ser evitada, pode ser considerada a administração da vacina se o doente apresentar um compromisso ligeiro da imunidade, como infeção por vírus da imunodeficiência humana $(\mathrm{VIH})$ com contagens de linfócitos CD4 superiores a $200 \mu \mathrm{L}$ ou défices ligeiros da imunidade humoral. ${ }^{2}$

\section{Vacinação de conviventes}

Os conviventes de indivíduos com compromisso da imunidade inata ou adquirida devem ser vacinados de acordo com o PNV e, anualmente, com a vacina contra a gripe inativada. ${ }^{5}$ Se existirem esquemas vacinais incompletos, devem ser aconselhados a completá-los se se tratarem de vacinas inativadas e recombinantes, já que estas não apresentam risco para os indivíduos imunodeprimidos. ${ }^{2}$

A vacinação com vacinas vivas de conviventes de pessoas com imunodeficiência pode exigir precauções especiais:

- A vacina oral contra a poliomielite viva atenuada (VAP) é contraindicada (não utilizada atualmente na Europa $)^{2}$;

- A vacina contra o vírus varicela-zoster (VVZ) é 
Tabela 1 - Principais fármacos imunomoduladores/imunossupressores utilizados no tratamento das doenças autoimunes ou autoinflamatórias ${ }^{1,26}$

\begin{tabular}{|c|c|c|}
\hline \multirow[t]{13}{*}{ Agentes não dirigidos } & \multirow[t]{4}{*}{ Glucocorticoides } & Budesonida \\
\hline & & Hidrocortisona \\
\hline & & Metilprednisolona \\
\hline & & Prednisolona \\
\hline & \multirow[t]{5}{*}{ Citostáticos } & 6-Mercaptopurina \\
\hline & & Azatioprina \\
\hline & & Cladribina \\
\hline & & Metotrexato \\
\hline & & Micofenolato de mofetil \\
\hline & Inibidores da calcineurina & Ciclosporina \\
\hline & \multirow[t]{2}{*}{ Ácido 5-aminosalicílico e derivados } & Mesalazina \\
\hline & & Sulfassalazina \\
\hline & Derivados do ácido fumárico & Fumarato de dimetilo \\
\hline \multirow[t]{35}{*}{ Terapêuticas biológicas dirigidas } & \multirow[t]{5}{*}{ Anti-TNF } & Adalimumab \\
\hline & & Certolizumab \\
\hline & & Etanercept \\
\hline & & Golimumab \\
\hline & & Infliximab \\
\hline & \multirow{4}{*}{ Anti-IL-1 } & Anakinra \\
\hline & & Canakinumab \\
\hline & & Gevokizumab \\
\hline & & Rilonacept \\
\hline & \multirow[t]{2}{*}{ Anti-IL-5 } & Mepolizumab \\
\hline & & Reslizumab \\
\hline & \multirow[t]{2}{*}{ Anti-IL-6 } & Siltuximab \\
\hline & & Tocilizumab \\
\hline & Anti-IL-12/23 & Ustekinumab \\
\hline & \multirow{3}{*}{ Anti-IL-17 } & Brodalumab \\
\hline & & Ixecizumab \\
\hline & & Secukinumab \\
\hline & Anti-imunoglobulina $\mathrm{E}$ & Omalizumab \\
\hline & Anti-complemento & Eculizumab \\
\hline & \multirow[t]{9}{*}{ Anti-CD20 } & Obinutuzumab \\
\hline & & Ocaratuzumab \\
\hline & & Ocrelizumab \\
\hline & & Ofatumumab \\
\hline & & Rituximab \\
\hline & & Ublituximab \\
\hline & & Veltuzumab \\
\hline & & 131I-Tositumomab \\
\hline & & 90Y-Ibritumomab tiuxetan \\
\hline & Anti-CD52 & Alemtuzumab \\
\hline & \multirow[t]{2}{*}{ Inibidores da PD-1 e da PD-L1 } & Atezolizumab \\
\hline & & Pembrolizumab \\
\hline & \multirow{3}{*}{ Inibidores das integrinas- $\alpha$} & Efalizumab \\
\hline & & Natalizumab \\
\hline & & Vedolizumab \\
\hline & Moduladores do recetor da S1P & Fingolimod \\
\hline
\end{tabular}

IL: interleucina; PD-: proteína de morte celular programada 1 (programmed cell death protein 1); PD-L1: ligante de morte celular programada 1 (programmed death-ligand 1); S1P: esfingosina-1-fosfato; TNF: fator de necrose tumoral 
recomendada em conviventes não imunizados e pode ser administrada, mas, no caso de o convivente desenvolver reação cutânea compatível com infeção por estirpe vacinal, deve ser evitado o contacto próximo com o indivíduo imunocomprometido até resolução das lesões;

- Indivíduos imunodeprimidos devem evitar manusear as fraldas de crianças vacinadas há menos de quatro semanas com a vacina contra o rotavírus, devendo promover-se a higienização frequente das mãos dos conviventes que as manuseiam. ${ }^{2}$

\section{Vacinação contra a COVID-19}

A vacinação contra a doença pelo coronavírus de 2019 (COVID-19 - coronavirus disease 2019) é, atualmente, o principal meio de prevenção da doença. Os doentes sob imunossupressores devem ser vacinados assim que possível. ${ }^{6}$ As recomendações americanas apontam para que a população com doença autoimune e autoinflamatória seja prioritária nas listas de vacinação em relação à população saudável da mesma idade. ${ }^{6}$ É também recomendada a vacinação dos seus conviventes, embora não pertençam a grupo prioritário. ${ }^{6}$ Em Portugal, os indivíduos sob terapêutica

Tabela 2 - Administração de vacinas vivas atenuadas em indivíduos com alterações da imunidade $e^{2,64,65}$

\begin{tabular}{|c|c|c|c|}
\hline Vacina & Esquema vacinal & Indicações & Contraindicações \\
\hline VASPR & De acordo com PNV & Vacinação universal & $\begin{array}{l}\text { - Reação alérgica a componente da vacina } \\
\text { - Infeção por VIH sintomática ou com }\end{array}$ \\
\hline $\begin{array}{l}\text { Vacina contra VVZ } \\
\text { (varicela) }\end{array}$ & $\begin{array}{l}2 \text { doses } \\
\text { (separadas por pelo } \\
\text { menos } 4 \text { semanas)* }\end{array}$ & $\begin{array}{l}\text { Todos os indivíduos } \\
\text { imunocompetentes que vão iniciar } \\
\text { imunossupressão farmacológica } \\
\text { e que não apresentam anticorpos } \\
\text { contra VVZ }\end{array}$ & $\begin{array}{ll} & \text { contagem de linfócitos } T C D 4<200 / \mu L^{\ddagger} \\
\text { - } & \text { Neoplasias hematológicas ativas sob QT } \\
\text { - } & \text { Neoplasias de órgão sólido sob QT } \\
\text { - } & \text { Neoplasias de órgão sólido após RT } \\
\text { - } & \text { Tratamento com agentes } \\
\text { imunomoduladores: }\end{array}$ \\
\hline $\begin{array}{l}\text { Vacina contra VVZ } \\
\text { (herpes zoster) }\end{array}$ & Dose única* & $\begin{array}{l}\text { Indivíduos com mais de } 60 \text { anos } \\
\text { que vão iniciar imunossupressão } \\
\text { Considerar em indivíduos com } \\
50 \text { - } 59 \text { anos se história de infeção } \\
\text { prévia por VVZ e risco elevado } \\
\text { de reativação após início de } \\
\text { imunossupressão }\end{array}$ & $\begin{array}{l}\text { - Terapêutica biológica } \\
\text { - Corticoterapia em alta dose (equivalente a } \\
\geq 20 \mathrm{mg} \text { de prednisolona/dia) } \\
\text { - Alquilantes (ciclofosfamida) } \\
\text { - Antimetabolitos nas seguintes doses: } \\
\text { Azatioprina }>3 \mathrm{mg} / \mathrm{kg} / \mathrm{dia} \\
\text { 6-mercaptopurina }>1,5 \mathrm{mg} / \mathrm{kg} / \mathrm{dia} \\
\text { Metotrexato }>0,4 \mathrm{mg} / \mathrm{kg} / \mathrm{semana}\end{array}$ \\
\hline $\begin{array}{l}\text { Vacina contra o } \\
\text { vírus da febre } \\
\text { amarela }\end{array}$ & Dose única $^{\dagger}$ & $\begin{array}{l}\text { Viagens para regiões endémicas } \\
\text { Pode ser obrigatória em } \\
\text { determinados países }\end{array}$ & $\begin{array}{l}\text { - } \quad \text { Transplantados de órgãos sólidos } \\
\text { - } \text { nos primeinaros dois anos sob } \\
\text { imunossupressor } \\
\text { - Imunodeficiências primárias } \\
\text { - Anemia aplásica }\end{array}$ \\
\hline
\end{tabular}

*Administradas quatro semanas antes do início da imunossupressão.

† Indicações para realização de reforço vacinal: gravidez (reforço antes da próxima viagem de risco); pós-transplante de células hematopoiéticas (reforço antes da próxima viagem de risco); infeção por VIH (a cada 10 anos).

‡ Recomenda-se precaução em indivíduos com infeção por VIH assintomática e com linfócitos T CD4 entre 200 e $499 \mu \mathrm{L}$.

$\S$ Geralmente a imunidade recupera-se três meses após suspensão de imunossupressor (até 18 meses no caso de anti-CD20) ou um mês após suspensão de corticoterapia.

PNV: programa nacional de vacinação; QT: quimioterapia; RT: radioterapia; VASPR: vacina anti-sarampo, parotidite e rubéola; VIH: vírus da imunodeficiência humana; VVZ: vírus varicela-zoster.

Tabela 3 - Duração mínima da imunossupressão de acordo com o fármaco ${ }^{3,4}$

\begin{tabular}{ll}
\hline Fármaco imunossupressor & Duração da imunossupressão \\
\hline Ácido micofenólico & 5 dias \\
Alemtuzumab & Superior a 1 ano \\
Azatioprina & 2 meses \\
Ciclosporina & 7 dias \\
Corticoterapia em alta dose em indivíduos com esclerose múltipla & 3 meses \\
Etanercept & 1 mês \\
Infliximab, adalimumab, golimumab, cetolizumab & 3 meses \\
Metotrexato & 1 mês \\
Prednisolona & 1 mês \\
Rituximab & 1 ano \\
Tacrolimus & 3 dias \\
\hline
\end{tabular}


imunossupressora ou com doença autoimune não constituem atualmente grupos prioritários de vacinação. ${ }^{7}$

Dado não se tratarem de vacinas vivas, não existe qualquer contraindicação à vacinação neste grupo de doentes; contudo, a imunogenicidade e eficácia da vacina poderão ser menores do que na população geral. Em relação ao timing da vacina, alguns peritos recomendam adiar a administração de alguns imunossupressores ou ajustar o timing da vacinação por forma a tentar otimizar a resposta imunitária à imunização. De acordo com as recomendações emitidas pela American College of Rheumatology 6 :

- Metotrexato: Nos doentes com doença estabilizada, suspender durante uma semana após cada dose da vacina.

- Abatacept subcutâneo: suspender uma semana antes e uma semana depois da primeira dose da vacina (apenas); não há necessidade de interrupção na segunda dose.

- Abatacept endovenoso: agendar vacinação de forma a que a primeira dose seja administrada quatro semanas após a infusão e adiar a dose subsequente por uma semana (intervalo entre doses de cinco semanas).

- Ciclofosfamida endovenosa: Se possível, agendar a administração para aproximadamente uma semana após cada dose da vacina.

- Glucocorticoides em dose equivalente inferior a 20 $\mathrm{mg} / \mathrm{dia}$ de prednisolona; sulfassalazina; leflunomida; micofenolato de mofetil; azatioprina; ciclofosfamida oral; anti-fator de necrose tumoral (anti-TNF); anti-interleucina (IL) 6R; anti-IL-1; anti-IL-17; anti-IL-12/23; anti-IL-23; belimumab; inibidores da calcineurina: não está recomendado ajuste no timing da vacinação nem da administração dos fármacos.

- Glucocorticoides em dose equivalente a superiores ou iguais a $20 \mathrm{mg} / \mathrm{dia}$ de prednisolona: não existe consenso, embora a maioria dos peritos não recomende ajuste no timing da vacinação nem da administração do fármaco.

- Rituximab: Agendar a vacinação por forma a que seja iniciada aproximadamente quatro semanas antes do próximo ciclo de rituximab. Após a vacinação, protelar a administração de rituximab até duas a quatro semanas após a segunda dose da vacina, se a atividade da doença o permitir.

- Inibidores da Janus kinase (JAK): interromper administração do fármaco durante uma semana após cada dose vacinal.

Este é um tema recente e mais estudos serão necessários para gerar evidência robusta relativamente à eficácia vacinal neste grupo de doentes. Desta forma, todos os doentes imunossuprimidos, ainda que vacinados, devem manter precauções para minimizar o risco de transmissão (uso de máscaras, distanciamento social e evicção de aglomerados populacionais)
TUBERCULOSE: RASTREIO, TRATAMENTO E QUIMIOPROFILAXIA

O TNF- $\alpha$ e as interleucinas (IL-) 1, 6, 12 e 17 são considerados essenciais na resposta imune contra Mycobacterium tuberculosis (MT); consequentemente, fármacos que os têm como alvo associam-se a maior risco de infeção por esta micobactéria. ${ }^{8} \mathrm{~A}$ magnitude desse risco é variável de acordo com o tipo de fármaco utilizado, sendo mais elevado para os anticorpos monoclonais inibidores de TNF- $\alpha{ }^{9}$

A tuberculose (TB) no contexto de terapêutica imunossupressora resulta habitualmente de reativação de infeção latente. ${ }^{10}$ Assim, o rastreio sistemático é uma recomendação praticamente universal nos doentes candidatos a imunossupressão biológica. Esse rastreio deve ser realizado antes do início do fármaco imunossupressor e deve ser repetido anualmente se o primeiro rastreio for negativo ou mais cedo se houver, entretanto, exposição a doente com tuberculose ativa.

O rastreio deve começar pela exclusão de doença ativa através do inquérito de sintomas, pesquisa de sinais compatíveis com doença e telerradiografia de tórax. Se o doente apresentar achados clínicos ou radiológicos sugestivos de doença ativa, deve proceder-se a respetiva investigação diagnóstica e protelado o início da imunossupressão.

Depois de excluída doença ativa, deve realizar-se rastreio de infeção latente (TBIL) (Fig. 1). É essencial uma história clínica pormenorizada, com especial enfoque na história passada de TB ou TBIL, tratamento instituído, história de estadia prolongada em países de alta endemicidade e história de exposição passada a doente com tuberculose. Os testes disponíveis para rastreio de TBIL - teste de sensibilidade à tuberculina (TST) e interferon-gamma release assays (IGRA) - apresentam inúmeras limitações; em doentes imunossuprimidos, a sensibilidade de ambos pode estar comprometida. ${ }^{11}$ Assim, no doente imunodeprimido recomenda-se a realização dos dois testes em simultâneo, e um resultado positivo em qualquer um dos dois testes deve ser valorizado. ${ }^{10}$

As recomendações nacionais apontam para que se mantenha rastreio anual em todos os doentes sob fármacos imunossupressores. ${ }^{12}$ Os doentes que apresentem ambos os testes imunológicos de rastreio positivos e que tenham sido tratados em conformidade devem ser monitorizados anualmente através da pesquisa de sinais e sintomas de TB. ${ }^{10}$ Os doentes que apresentem apenas um dos testes positivos (TST ou IGRA) devem também ser monitorizados anualmente através da pesquisa de sinais e sintomas de TB, não devendo o teste que foi positivo ser repetido em nenhuma circunstância; alguns especialistas recomendam também que seja repetido apenas o teste que era inicialmente negativo, usando-o para continuação de rastreio de TBIL.

$\mathrm{Na}$ presença de indicação para tratamento de TBIL, existem várias opções de tratamento disponíveis (Tabela $5),{ }^{13}$ devendo ser cumpridas pelo menos quatro semanas de tratamento antibacilar antes do início do fármaco imunossupressor. ${ }^{14} \mathrm{Em}$ situações em que a doença de base 0 
exija, pode ser aceitável iniciar precocemente a imunossupressão, desde que seja excluída tuberculose ativa. ${ }^{15}$

\section{REATIVAÇÃO DO VÍRUS DA HEPATITE B}

Mesmo na presença de evidência de recuperação serológica, o vírus da hepatite $\mathrm{B}(\mathrm{VHB})$ pode persistir por integração do ácido desoxirribonucleico (ADN) vírico no genoma dos hepatócitos. Indivíduos com evidência de infeção prévia que recebam imunossupressores encontram-se em risco de reativação do vírus da hepatite $\mathrm{B}$ ( $\mathrm{rVHB}$ ), que pode ser grave, com taxas de mortalidade reportadas de até $25 \% .^{16}$

Tabela 4 - Principais vacinas administradas em contexto de imunomodulação, suas indicações e esquemas de administração

\begin{tabular}{|c|c|}
\hline Vacina & Indicações \\
\hline $\begin{array}{l}\text { Vacina contra a gripe } \\
\text { (inativada tetravalente) }\end{array}$ & $\begin{array}{l}\text { Grupos prioritários } 2,66,67 \text { : idosos ( } \geq 65 \text { anos); doentes crónicos; imunodeprimidos; grávidas; } \\
\text { profissionais de saúde. }\end{array}$ \\
\hline $\begin{array}{l}\text { Vacinas antipneumocócicas: } \\
\left.\text { vacina conjugada (Prevenar } 13^{\circledR}\right) \\
\text { e vacina polissacarídea } \\
\left(\text { Pneumovax } 23^{\circledR}\right)\end{array}$ & $\begin{array}{l}\text { História de doença pneumocócica invasiva e indivíduos com fatores de risco para doença } \\
\text { pneumocócica ou com risco para infeções graves e de mau prognóstico }{ }^{2,66,67} \text { : idosos ( } \geq 65 \text { anos); } \\
\text { cardiopatia; doença pulmonar crónica; doença renal crónica; doença hepática crónica; diabetes } \\
\text { mellitus não controlada; tabagismo; etilismo; asplenia; doença falciforme; infeção por VIH; } \\
\text { neoplasia hematológica ou disseminada; transplante de órgão; imunossupressão iatrogénica } \\
\text { (incluindo corticoterapia prolongada e radiação); imunodeficiência congénita ou adquirida. }\end{array}$ \\
\hline
\end{tabular}
hepatite $\mathrm{B}$ (Engerix $\mathrm{B}^{\circledR}$ )

Vacina contra o vírus da hepatite $\mathrm{A}\left(\mathrm{Havrix}^{\circledR}\right.$ ou VAQTA $\left.{ }^{\circledR}\right)$
Vacina contra o vírus da

Imunocomprometidos ou candidatos a imunossupressão não imunizados ao abrigo do PNV (sem história vacinal ou com anti-HBs $<10 \mathrm{mlU} / \mathrm{mL}) .^{71}$

Imunocomprometidos ou candidatos a imunossupressão em risco de contrair infeção por VHA. ${ }^{73}$ Viajantes para áreas endémicas; pertencentes a comunidades onde ocorra um surto; homens que praticam sexo com homens; doença hepática crónica.

Indivíduos com > 18 anos, imunocomprometidos ou candidatos a imunossupressão e em risco de contrair infeção pelos vírus da hepatite A e hepatite $B .^{75}$

Vacina contra os vírus das hepatites A e B (Twinrix ${ }^{\circledR}$ )

Vacinas contra Neisseria
meningitidis:
vacina contra o grupo B
$\left(\right.$ Bexsero ${ }^{\circledR}$ e
vacina contra os grupos A, C,
$\mathrm{W}_{135}$ e Y
(Menveo $^{\circledR}$ ou Nimenrix $\left.{ }^{\circledast}\right)$

Vacina contra o vírus do papiloma humano (Gardasil $9^{\circledR}$ )

Vacina contra o sarampo, parotidite epidémica e rubéola (VASPR)

Vacina contra a varicela (Varilrix ${ }^{\circledR}$ ou Varivax ${ }^{\circledR}$ )

Vacina contra reativação do VVZ (Zostavax ${ }^{\circledR}$ ou Shingrix ${ }^{\circledR}$ )
Indivíduos em risco de doença meningocócica invasiva ${ }^{2,74}$ : esplenectomizados/hipoesplenismo; défice congénito de complemento; terapêutica com inibidores do complemento (eculizumab).

Estudantes universitários que moram em residências, viajantes ou residentes em áreas onde a doença meningocócica é endémica ou hiperendémica, indivíduos em risco durante um surto na comunidade, recrutas militares ou microbiologistas expostos a $N$. meningitidis. ${ }^{2,74}$

Indivíduos em risco durante um surto na comunidade por $N$. meningitidis do grupo $\mathrm{B}^{2,74}$ Indivíduos sexualmente ativos e candidatos a imunossupressão, não imunizados. ${ }^{75,76}$

Indivíduos candidatos a imunossupressão não imunizados. ${ }^{2,64,65}$

Imunocompetentes ${ }^{\S}$ que vão iniciar imunossupressão e sem contato prévio com VVZ. ${ }^{2}$

Zostavax ${ }^{\circledR}$ (vacina viva atenuada): indivíduos com $>60$ anos e contato prévio com VVZ que irão iniciar imunossupressão²; indivíduos entre os 50 - 59 anos se risco elevado de reativação de VVZ após início de imunossupressão). ${ }^{2}$

Shingrix ${ }^{\circledR}$ (vacina inativada recombinante): indivíduos com > 50 anos e contato prévio com VVZ, imunocomprometidos ou que irão iniciar imunossupressão. ${ }^{77}$

* Avaliar título de anticorpo HBs um a dois meses após a terceira dose: se anti-HBs for inferior a $10 \mathrm{mlU} / \mathrm{mL}$, pode realizar-se esquema alternativo com o dobro da dose (40 $\mu \mathrm{g})$, mantendo o esquema temporal. 2,69

${ }^{\dagger}$ A vacinação deverá ser administrada duas a quatro semanas antes da esplenectomia ou início do eculizumab. ${ }^{2}$

* O esquema deve estar completo pelo menos quatro semanas antes do início da imunossupressão.

$\S$ Pode considerar-se em indivíduos com défices ligeiros de imunidade (défice primário de complemento ou doença granulomatosa crónica) ${ }^{2}$. 
A determinação do AgHBs, anti-HBs e anti-HBc deve ser efetuada em todos os candidatos a terapêutica imunossupressora. ${ }^{17} \mathrm{~A}$ rVHB é mais frequentemente observada na infeção com AgHBs positivo, ocorrendo também em doentes com anti-HBc isolado ou cura funcional (isto é, AgHBs negativo com anti-HBc positivo). ${ }^{18}$
Na maioria dos casos, a rVHB é assintomática, determinada apenas pelo aumento dos valores de ADN VHB. ${ }^{19}$ Define-se como:

- na presença de AgHBs positivo, aumento do ADN VHB 100 vezes ( $\geq 2 \log \mathrm{UI} / \mathrm{mL}$ ) comparativamente ao valor de base, aumento do ADN VHB $\geq 3$ log

\section{Esquema de administração}

Via IM, dose única anual, antes do início da atividade do vírus na comunidade (final de outubro no hemisfério norte e final de abril no hemisfério sul). $2,66,67$

Prevenar $13^{\circledR}$ : via IM;

Pneumovax $23^{\circledR}$ : via IM ou SC.

Imunocompetentes e com risco para doença pneumocócica: dose única de Pneumovax $23^{\circledR} .66,67$ Pode ser considerada a administração de uma dose de Pneumovax $23^{\circledR}$ a cada 10 anos, ${ }^{68}$ se existir risco muito elevado de doença invasiva.

Imunodeprimidos ou com história de doença pneumocócica invasiva: uma dose de Prevenar $13^{\circledR}$, seguida de uma dose de Pneumovax $23^{\circledR}$ após 6 - 12 meses (mínimo 8 semanas). ${ }^{2,66,67,68}$ A Prevenar $13^{\circledR}$ deve ser administrada pelo menos 1 ano após a última dose de Pneumovax $23^{\circledR}{ }^{2,66,67,69}$ Os CDC propõem a revacinação com apenas uma dose de Pneumovax $23^{\circledR} 5$ anos após a primeira ${ }^{66,67}$; outros autores recomendam a revacinação a cada 5 - 7 anos em indivíduos com asplenia, fístula de líquor e implantes cocleares e a cada 5 - 10 anos em imunodeprimidos por outras causas. ${ }^{68}$

A revacinação com a Prevenar $13^{\circledR}$ não está indicada. ${ }^{70}$

Via IM, esquema de 3 doses*:

Esquema normal: 0, 1 e 6 meses $^{5}$;

Esquema acelerado ${ }^{72}: 0,1$ e 2 meses +12 meses (reforço) $)^{72}$

Esquema super-acelerado: 0,7 e 21 dias +12 meses (reforço). ${ }^{72}$

Via IM, esquema de 2 doses $^{73}$ :

Havrix $^{\circledR}:$ 0, 6-12 meses;

VAQTA $^{\circledR}$ : 0, 6 - 18 meses.

Se imunocomprometido e viagem em $<2$ semanas para zona endémica:

$1^{\text {a }}$ dose da vacina deve ser administrada com 1 dose de $\lg \mathrm{VHA} .{ }^{73,74}$

Via IM, esquema de 3 doses:

Esquema normal: 0, 1 e 6 meses $^{73}$;

Esquema acelerado: 0, 7 e 21 dias +12 meses (reforço). ${ }^{75}$

Vacina contra N. meningitidis do grupo B: Via IM, esquema de 2 doses separadas de $\geq 1$ mês, com 1 dose de reforço 1 ano após a conclusão da vacinação primária e doses de reforço subsequentes a cada 2 - 3 anos. ${ }^{\dagger 2,74}$

Vacina contra N. meningitidis $\mathrm{ACW}_{135} \mathrm{Y}$ : Via IM, esquema de 2 doses separadas por $\geq 8$ semanas, com 1 dose de reforço a cada 5 anos. $^{\dagger 2,74}$

Vacina contra $N$. meningitidis $\mathrm{ACW}_{135} \mathrm{Y}$ : Via IM, dose única, com 1 dose de reforço a cada 5 anos se se mantiver o risco.,74

Vacina contra N. meningitidis do grupo B: Via IM, esquema de 2 doses separadas de $\geq 1$ mês. ${ }^{2,74}$

Via IM, esquema de 3 doses: 0,2 e 6 meses. $^{76}$

Via IM, esquema de 2 doses separadas de, pelo menos, 28 dias. ${ }^{\ddagger 2,64,65}$

Via IM, esquema de 2 doses administradas com, pelo menos, 4 semanas de intervalo. ${ }^{\ddagger}$

Via IM ou SC, dose única. ${ }^{77}$

Via IM, esquema de 2 doses separadas de, pelo menos, 2 a 6 meses. $^{77}$ 


\section{Candidato a iniciar imunossupressão}

Doente sob imunossupressor

- $\quad$ Radiografia ou TC de tórax com alterações compatíveis com sequelas de TB e sem história de tratamento adequado

- História prévia de TB sem tratamento adequado

- Risco epidemiológico

- História de contacto com doente com TB

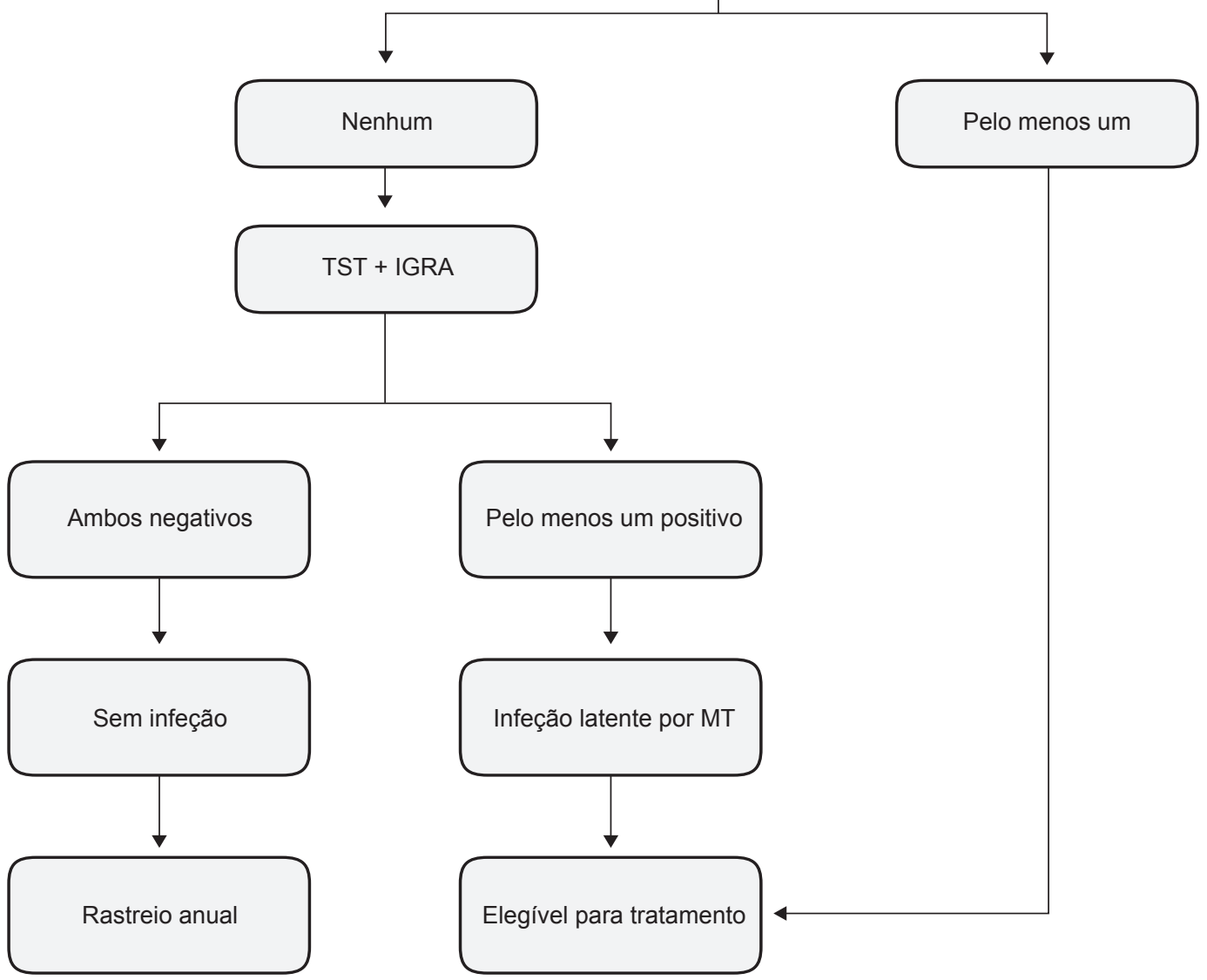

Figura 1 - Algoritmo de rastreio e indicações para tratamento de tuberculose latente. ${ }^{12}$

IGRA: Interferon Gamma release assays; MT: Mycobacterium tuberculosis; TB: tuberculose; TC: tomografia computorizada; TST: teste de sensibilidade à tuberculina. 
(1000 Ul/mL) se de novo, ou aumento no ADN VHB $\geq 4 \log (10000 \mathrm{UI} / \mathrm{mL})$ se o valor basal não estiver disponível;

- se AgHBs negativo e anti-HBc positivo, presença de ADN VHB detetável ou serorreversão do AgHBs. ${ }^{20}$

As recomendações de instituição de terapêutica profilática ou de antecipação variam com o regime imunossupressor (Tabela 6). Se for instituída profilaxia antivírica, recomenda-se o seu início antes (sete dias) ou simultaneamente com o imunossupressor, ${ }^{20}$ excetuando se o ADN $\mathrm{VHB}$ for $>4 \log \mathrm{UI} / \mathrm{mL}$, caso em que se recomenda atraso do início da terapêutica imunossupressora até ADN VHB < $3 \log \mathrm{UI} / \mathrm{mL}$.

Os análogos dos nucleós(t)idos com alta barreira genética (entecavir ou tenofovir) apresentam maior eficácia na prevenção da rVHB e devem ser preferidos à lamivudina. ${ }^{17,18} \mathrm{Em}$ doentes naïve de tratamento, sugere-se tenofovir ou entecavir. Em doentes que receberam terapêutica prévia com lamivudina, é preferível a utilização de tenofovir (alta taxa de resistência a entecavir em doentes refratários à lamivudina).

Se for instituída profilaxia antivírica, o valor basal de ADN VHB deve ser determinado antes do seu início, e a função hepática e o ADN VHB devem ser monitorizados cada 3 - 6 meses e durante pelo menos 12 meses após a interrupção do antivírico. ${ }^{17,20}$

Nos doentes com AgHBs negativo e anti-HBc positivo, se não for implementada profilaxia antivírica, a função hepática e o ADN VHB devem ser monitorizados cada 1 - 3 meses durante e após a imunossupressão. 17,20

\section{INFEÇÃO POR VÍRUS JOHN CUNNINGHAM}

A infeção pelo vírus John Cunningham (VJC) e subsequente leucoencefalopatia multifocal progressiva (LMP) ocorrem em contexto de imunossupressão celular grave. As principais condições predisponentes são as neoplasias ${ }^{21}$ infeção por VIH com depressão imunológica grave, ${ }^{22}$ transplante de órgão, ${ }^{23}$ imunodeficiências primárias ${ }^{24}$ e determinadas doenças autoimunes. ${ }^{21}$ Existe um risco acrescido nos indivíduos sob anticorpos monoclonais, mas o natalizumab é o fármaco mais frequentemente associado a LMP. ${ }^{22,25,26}$ Os fatores de risco incluem linfopenia, imunossupressão prévia, duração prolongada do tratamento (acima de 48 meses), estado serológico para VJC pré-tratamento positivo e títulos elevados de anticorpo lgG anti-VJC. ${ }^{25,26}$

A única forma de prevenção da doença é a recuperação da imunidade. ${ }^{22} \mathrm{De}$ acordo com as orientações da Infectious Diseases Society of America (IDSA) e do ESCMID Study Group for Infections in Compromised Hosts (ESGI$\mathrm{CH}$ ), apenas os doentes sob natalizumab têm indicação para realização de rastreio de LMP. ${ }^{25}$ Antes do início do tratamento, deve ser avaliado o estado serológico para o VJC (através do índex quantitativo de anticorpos anti-VJC) e

Tabela 5 - Esquemas recomendados para tratamento de TBIL em imunodeprimidos ${ }^{12-14}$

\begin{tabular}{|c|c|c|}
\hline Esquema & Dose & Observações \\
\hline $9 \mathrm{H}$ & $\begin{array}{l}\text { Toma diária } \\
\text { Crianças: } 10 \text { mg/kg (máx. } 300 \text { mg) } \\
\text { Adultos: } 5 \text { mg/kg (máx. } 300 \text { mg) }\end{array}$ & $\begin{array}{l}\text { - Pode ser necessária suplementação com } \\
\text { piridoxina (40 - } 200 \mathrm{mg} / \mathrm{dia}) \\
\text { - Eficácia de aproximadamente } 90 \% \\
\text { - } \quad \text { Maiores taxas de abandono e efeitos } \\
\text { laterais do que os esquemas alternativos }\end{array}$ \\
\hline $4 R$ & $\begin{array}{l}\text { Toma diária } \\
\text { Crianças: } 10 \text { - } 20 \text { mg/kg (máx. } 600 \text { mg) } \\
\text { Adultos: } 10 \text { mg/kg (máx. } 600 \text { mg) }\end{array}$ & $\begin{array}{l}\text { - Eficácia semelhante a } 9 \mathrm{H} \\
\text { - Recomendado na toxicidade/ intolerância } \\
\text { - } \text { ou resistência à isoniazida } \\
\text { - Excluir interações medicamentosas }\end{array}$ \\
\hline 3HRpt * & $\begin{array}{l}\text { Toma semanal observada } \\
\text { H } \\
\text { Crianças e adolescentes: } 10 \text { - } 14 \mathrm{~kg}, 300 \mathrm{mg} ; 14 \text { - } 25 \mathrm{~kg}, 450 \mathrm{mg} \text {; } \\
25 \text { - } 32 \mathrm{~kg}, 600 \mathrm{mg} ; 32 \text { - } 50 \mathrm{~kg}, 750 \mathrm{mg} ; \geq 50 \mathrm{~kg}, 900 \mathrm{mg} \\
\text { Adultos: } 15 \mathrm{mg} / \mathrm{kg} \text { (máx. } 900 \mathrm{mg} \text { ) } \\
\text { Rpt } \\
10-14 \mathrm{~kg}, 300 \mathrm{mg} ; 14-25 \mathrm{~kg}, 450 \mathrm{mg} ; 25-32 \mathrm{~kg}, 600 \mathrm{mg} \text {; } \\
32-50 \mathrm{~kg}, 750 \mathrm{mg} ; \geq 50 \mathrm{~kg}, 900 \mathrm{mg} \text { (máx.) }\end{array}$ & $\begin{array}{l}\text { - Não recomendado em grávidas e crianças } \\
\text { - } 2 \text { anos } \\
\text { - } \quad \text { Podeluir interações medicamentosas } \\
\text { piridoxina (40 - } 200 \mathrm{mg} / \mathrm{dia})\end{array}$ \\
\hline 3HR & $\begin{array}{l}\text { Toma diária } \\
\text { H } \\
\text { Crianças: } 10 \mathrm{mg} / \mathrm{kg} \text { (máx. } 300 \mathrm{mg} \text { ) } \\
\text { Adultos: } 5 \mathrm{mg} / \mathrm{kg} \text { (máx. } 300 \mathrm{mg} \text { ) } \\
\mathrm{R} \\
\text { Crianças: } 10 \text { - } 20 \mathrm{mg} / \mathrm{kg} \text { (máx. } 600 \mathrm{mg} \text { ) } \\
\text { Adultos: } 10 \mathrm{mg} / \mathrm{kg} \text { (máx. } 600 \mathrm{mg} \text { ) }\end{array}$ & $\begin{array}{l}\text { - Considerar apenas em situações } \\
\text { excecionais } \\
\text { - Excluir interações medicamentosas } \\
\text { - Pode ser necessária suplementação com } \\
\text { piridoxina (40 - } 200 \mathrm{mg} / \mathrm{dia})\end{array}$ \\
\hline
\end{tabular}

\footnotetext{
$\mathrm{H}$ : isoniazida; R: rifampicina; Rpt: rifapentina; TBIL: tuberculose - infeção latente
}

* não disponível em Portugal 
Tabela 6 - Risco de rVHB e atitudes recomendadas ${ }^{15,18}$

\begin{tabular}{|c|c|c|}
\hline \multicolumn{3}{|c|}{ Alto risco de rVHB (> $10 \%)$} \\
\hline \multirow[t]{2}{*}{ AgHBs positivo } & Depletores de células $\mathrm{B}^{\dagger}$ & $\begin{array}{l}\text { Profilaxia antivírica até pelo menos } 12 \text { - } 18 \text { meses após } \\
\text { descontinuação do imunossupressor. }\end{array}$ \\
\hline & $\begin{array}{l}\text { Derivados das antraciclinas }{ }^{\ddagger} \\
\text { Regimes pós-TCH sem corticoide } \\
\text { Anti-CD52" } \\
\text { CCT em doses altas/moderadas } \geq 4 \text { semanas }^{\llbracket}\end{array}$ & $\begin{array}{l}\text { Profilaxia antivírica até pelo menos } 6 \text { - } 12 \text { meses após } \\
\text { descontinuação do imunossupressor. }\end{array}$ \\
\hline $\begin{array}{l}\text { AgHBs negativo } \\
\text { Anti-HBc positivo }\end{array}$ & Depletores de células $\mathrm{B}^{\dagger}$ & $\begin{array}{l}\text { Profilaxia antivírica até pelo menos } 12 \text { - } 18 \text { meses após } \\
\text { descontinuação do imunossupressor. }\end{array}$ \\
\hline \multicolumn{3}{|c|}{ Risco moderado de rVHB (1\% - $10 \%)$} \\
\hline AgHBs positivo & $\begin{array}{l}\text { Anti-TNF** } \\
\text { Outros inibidores das citocinas/integrinas }{ }^{\dagger \dagger} \\
\text { Inibidores da tirosina cinase } \\
\text { CCT em doses baixas } \geq 4 \text { semanas } \\
\text { Outra QT citotóxica sem corticoide } \\
\text { Regimes pós-TOS sem corticoide } \\
\text { R }\end{array}$ & $\begin{array}{l}\text { Profilaxia antivírica até } 6 \text { - } 12 \text { meses após descontinuação do } \\
\text { imunossupressor. }\end{array}$ \\
\hline $\begin{array}{l}\text { AgHBs negativo } \\
\text { Anti-HBc positivo }\end{array}$ & $\begin{array}{l}\text { Anti-TNF** } \\
\text { Outros inibidores das citocinas/integrinas }{ }^{\dagger \dagger} \\
\text { Inibidores da tirosina cinase }^{\ddagger \ddagger} \\
\text { CCT em doses altas/moderadas } \geq 4 \text { semanas }^{\pi} \\
\text { Derivados das antraciclinas }^{\ddagger} \\
\text { Regimes pós-TCH sem corticoide }^{\S}\end{array}$ & $\begin{array}{l}\text { Opção* de iniciar profilaxia antivírica (até pelo menos } 6 \text { meses } \\
\text { após descontinuação do imunossupressor) ou monitorizar } \\
\text { DNA VHB cada } 1 \text { - } 3 \text { meses durante e após imunossupressão, } \\
\text { iniciando antivírico (terapêutica de antecipação) se DNA VHB } \\
\text { detetável ou serorreversão AgHBs. }\end{array}$ \\
\hline \multicolumn{3}{|c|}{ Baixo risco de rVHB (<1\%) } \\
\hline AgHBs positivo & $\begin{array}{l}\text { Imunossupressores tradicionais }{ }^{\text {IIII }} \\
\text { CCT em qualquer dose PO diária } \leq 1 \text { semana" } \\
\text { CCT intra-articular }\end{array}$ & $\begin{array}{l}\text { Profilaxia antivírica até pelo menos } 6 \text { - } 12 \text { meses após } \\
\text { descontinuação do imunossupressor. }\end{array}$ \\
\hline $\begin{array}{l}\text { AgHBs negativo } \\
\text { Anti-HBc positivo }\end{array}$ & $\begin{array}{l}\text { Imunossupressores tradicionais }{ }^{|l|} \\
\text { CCT em qualquer dose PO diária } \leq 1 \text { semanaף } \\
\text { CCT intra-articular } \\
\text { CCT em doses baixas } \geq 4 \text { semanas" } \\
\text { Anti-CD52" } \\
\text { Outra QT citotóxica sem corticoide }\end{array}$ & $\begin{array}{l}\text { Opção* de iniciar profilaxia antivírica ou monitorizar DNA } \\
\text { VHB cada } 1 \text { - } 3 \text { meses, iniciando antivírico (terapêutica de } \\
\text { antecipação) se DNA VHB detetável ou serorreversão AgHBs. }\end{array}$ \\
\hline 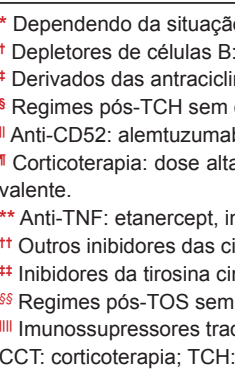 & $\begin{array}{l}\text { ca e da exequibilidade de monitorização apertada. } \\
\text { mab, ofatumumab, ocrelizumab, veltuzumab, obinutuzumab, oca } \\
\text { loxorrubicina, epirrubicina, daunorrubicina, idarrubicina, nemorru } \\
\text { oide: ciclosporina + metotrexato; tacrolimus + metotrexato; MMF } \\
\text { dnisolona > } 20 \mathrm{mg} / \text { dia ou equivalente; dose moderada, predniso } \\
\text { lab, adalimumab, certolizumab, golimumab } \\
\text { as/integrinas: abatacept, ustekinumab, natalizumab, vedolizumab } \\
\text { imatinib, nilotinib, dasatinib, bosutinib, ponatinib } \\
\text { oide: inibidores da calcineurina (ciclosporina, tacrolimus), sirolim } \\
\text { ais: azatioprina, metotrexato, 6-mercaptopurina } \\
\text { plante de células hematopoiéticas; TOS: transplante de órgão sć }\end{array}$ & $\begin{array}{l}\text { ratuzumab, ublituximab } \\
\text { icina, sabarrubicina, valrrubicina, pixantrona, mitoxantrone } \\
+ \text { ciclosporina/tacrolimus; globulina anti-timocítica } \\
\text { ona } 10-20 \mathrm{mg} / \text { dia ou equivalente; dose baixa, }<10 \mathrm{mg} / \text { dia de prednisolona ou equi- } \\
\text { efalizumab } \\
\text { Us, MMF } \\
\text { lido: QT: quimioterapia. }\end{array}$ \\
\hline
\end{tabular}

Tabela 7 - Monitorização durante o tratamento com natalizumab ${ }^{25,26}$

\begin{tabular}{|c|c|c|c|}
\hline & $\begin{array}{l}\text { Índex anti-VJC } \leq 0,9 \\
\text { ou seronegativo }\end{array}$ & $\begin{array}{l}\text { Índex anti-VJC } \\
>0,9 \text { e } \leq 1,5\end{array}$ & $\begin{array}{c}\text { Índex anti-VJC } \geq 1,5 \\
\text { ou imunossupressão prévia } \\
\text { (azatioprina, ciclofosfamida, } \\
\text { metotrexato, micofenolato) } \\
\text { ou } \geq 2 \text { anos sob natalizumab }\end{array}$ \\
\hline $\begin{array}{l}\text { Monitorização dos } \\
\text { títulos de anti-VJC }\end{array}$ & \multicolumn{2}{|c|}{$\begin{array}{c}\text { Aos } 12 \text { meses e posteriormente a cada } 6 \text { meses, até } 6 \text { meses } \\
\text { após a suspensão da terapêutica }\end{array}$} & Não indicada \\
\hline $\begin{array}{l}\text { Monitorização } \\
\text { imagiológica } \\
\text { por RMN CE }\end{array}$ & Anual & $\begin{array}{c}\text { Aos } 12 \text { e } 18 \text { meses e } \\
\text { posteriormente a cada } 6 \\
\text { meses }\end{array}$ & $\begin{array}{c}\text { Aos } 12 \text { e } 18 \text { meses e posteriormente } \\
\text { a cada } 6 \text { meses (considerar a cada } \\
3-4 \text { meses) }\end{array}$ \\
\hline
\end{tabular}

RMN CE: ressonância magnética nuclear cranioencefálica; VJC: vírus John Cunningham 
realizada neuroimagem com ressonância magnética (RM) cranioencefálica. ${ }^{25,26} \mathrm{~A}$ monitorização durante o tratamento, de acordo com o risco basal, deve seguir as recomendações descritas na Tabela 7.25,26

Em indivíduos com um índex superior a 0,9, deve ser considerada a suspensão da terapêutica aos 24 meses, para que o risco de LMP não seja significativamente elevado. ${ }^{25,26} \mathrm{Em}$ indivíduos previamente imunossuprimidos, esta suspensão deve ser considerada ao fim de 12 meses..$^{25,26}$ Um índex superior a 1,5 e/ou duração de tratamento superior a 48 meses devem condicionar a evicção ou descontinuação do fármaco. ${ }^{23}$

Não existe tratamento específico para a infeção por VJC ou LMP.22 A suspeita ou diagnóstico de LMP associada a natalizumab implica a descontinuação imediata do fármaco.

\section{INFEÇÃO POR HERPESVÍRUS}

\section{Infeção/doença por citomegalovírus}

Enquanto que nos doentes submetidos a transplante de órgão sólido e/ou sob tratamento para neoplasias hematológicas o risco de doença invasiva por citomegalovírus (CMV) está bem estabelecido, a evidência não é clara em doentes sob fármacos imunossupressores para tratamento de doenças autoimunes, não existindo, para estes, qualquer recomendação para rastreio ativo de doença por CMV. A existência de relatos de casos, designadamente em doentes sob fármacos anti-TNF- $\alpha^{27}$ e alemtuzumab, ${ }^{28}$ ainda que raros, deve alertar para esta possibilidade diagnóstica no caso de desenvolvimento de sintomas sugestivos.

\section{Infeção por herpes simplex 1 e 2}

A imunidade celular tem um papel preponderante na contenção da infeção primária por vírus herpes simplex (VHS) e na prevenção da reativação. Há relatos ocasionais de infeções recorrentes e/ou graves por VHS em doentes sob tratamentos biológicos com múltiplos fármacos. ${ }^{29,30}$ No entanto, são poucos aqueles que beneficiam de profilaxia antivírica:

- Doentes sob alemtuzumab devem realizar profilaxia antivírica com aciclovir (200 - 400 mg bid) desde o primeiro dia de cada ciclo de tratamento até perfazer 2 meses ou até que as contagens de CD4 recuperem até $>200 \mu \mathrm{L}^{31}$;

- Doentes sob fingolimod ou natalizumab que usem concomitantemente corticoterapia ou com infeções herpéticas recorrentes podem beneficiar de profilaxia antivírica. ${ }^{25}$

$\mathrm{Na}$ avaliação inicial de um doente candidato a iniciar imunossupressores biológicos deve constar a presença ou história de lesões herpéticas recorrentes e deve ser estabelecido o padrão serológico basal em relação a VHS-1 e VHS-2. Esta avaliação serológica será útil na determinação da necessidade de iniciar profilaxia nos grupos anteriormente descritos.

\section{Infeção por vírus varicela-zoster}

A primoinfeção por vírus varicela-zoster (VVZ) caracteriza-se por lesões vesiculares de base eritematosa e pruriginosas (varicela). Anos mais tarde, alguns indivíduos desenvolvem lesões neurocutâneas dolorosas causadas pela reativação do vírus - herpes zoster $(\mathrm{HZ})$. Alguns doentes imunocomprometidos, nomeadamente os que estão sob terapêuticas imunossupressoras específicas, ${ }^{32,33}$ têm maior risco de reativação de $\mathrm{VVZ} .^{34}$

Recomenda-se a avaliação de IgG VVZ em todos os candidatos a terapêutica imunossupressora. Se a lgG VVZ for negativa e o doente ainda não estiver imunossuprimido, deve realizar-se vacinação. Num doente imunossuprimido com exposição significativa ao vírus (doentes com varicela ou zoster), e se IgG VVZ negativa, recomenda-se a administração de imunoglobulina VVZ o mais brevemente possível após o contacto (no caso de desenvolvimento de sintomas, instituir tratamento). ${ }^{35}$

Existem atualmente estratégias de profilaxia de reativação de VVZ, incluindo medicação antivírica preventiva e vacinação. ${ }^{36}$ Os fármacos que causam maior depleção celular são aqueles que estão associados a maior risco de $\mathrm{HZ}$ :

- Doentes sob alemtuzumab devem realizar profilaxia antivírica com aciclovir, conforme descrito na secção anterior;

- Em doentes sob cladribina:

- Se a contagem de linfócitos for inferior a $500 \mu \mathrm{L}$, recomenda-se monitorização de sinais e sintomas sugestivos de infeção;

- Se a contagem de linfócitos for inferior a $200 \mu \mathrm{L}$, recomenda-se profilaxia anti-herpética. ${ }^{37}$

\section{PNEUMONIA POR PNEUMOCYSTIS JIROVECII}

A pneumonia por Pneumocystis jirovecii (PPj) é uma doença oportunista potencialmente grave em indivíduos imunocomprometidos. ${ }^{38}$ Os principais fatores de risco para a infeção incluem ${ }^{39}$ :

- Infeção por VIH;

- Fármacos imunossupressores;

- Corticoterapia;

- Neoplasias hematológicas (leucemia aguda, leucemia linfocítica crónica, linfoma não-Hodgkin, linfoma de Hodgkin, mieloma múltiplo e macroglobulinemia de Waldenstrom);

- Neoplasias de órgão sólido (neoplasia do sistema nervoso central - SNC e outros neoplasias);

- Recetores de transplante;

- Rejeição de órgão;

- Doenças inflamatórias;

- Doenças reumatológicas (poliarterite nodosa, granulomatose com poliangeíte e polimiosite/dermatopolimiosite);

- Imunodeficiências primárias graves;

- Desnutrição grave.

Os indivíduos sob corticoterapia em combinação com agentes citotóxicos ou quimioterapêuticos apresentam 
isco significativo para a infeção. Além disso, determinados fármacos estão associados a um maior risco de $\mathrm{PPj}$, incluindo alemtuzumab e infliximab. ${ }^{40} \mathrm{O}$ risco de PPj associado ao rituximab não é consensual. ${ }^{38,41}$

Não existe consenso sobre a possibilidade de determinadas doenças reumatológicas, na ausência de terapêutica imunossupressora, estarem ou não associadas a uma maior predisposição a PPj. ${ }^{42}$ Ainda assim, alguns autores apontam para um maior risco na polimiosite/dermatomiosite e na granulomatose com poliangeíte e um menor risco no lúpus eritematoso sistémico (LES). ${ }^{40}$ Por outro lado, indivíduos com doença de Crohn sob corticoterapia também apresentam maior risco infecioso. ${ }^{43}$

Não há recomendações publicadas sobre profilaxia de PPj na doença reumatológica ou doença inflamatória intestinal sob imunossupressão. ${ }^{42}$ Determinados autores defendem que a profilaxia deve ser usada quando o risco de PPj é superior a $6 \%{ }^{44}$; outros consideram o seu uso sempre que este risco é superior a 3,5\%. ${ }^{40}$ As indicações para profilaxia primária de $\mathrm{PPj}$ incluem:

- Infeção por VIH com contagem de CD4 inferior a $200 \mu \mathrm{L}^{45}$;

- Imunodeficiências primárias (imunodeficiência combinada grave, linfopenia de células T CD4 idiopática, síndrome de hiper-lgM) ${ }^{46}$;

- Indivíduos sob dose equivalente de prednisolona igual ou superior a $20 \mathrm{mg} / \mathrm{dia}$ durante um período igual ou superior a um mês, na presença de outra causa de imunossupressão (neoplasia hematológica, outros imunossupressores) $)^{47}$;

- Granulomatose com poliangeíte e vasculite associada aos ANCA sob prednisolona e ciclofosfamida ${ }^{40,42}$;

- Indivíduos sob alemtuzumab47;

- Indivíduos sob rituximab, sobretudo se em associação a quimioterapia ou dose elevadas de corticoterapia. ${ }^{38,48}$

Os regimes de primeira linha recomendados como profilaxia primária são: sulfametoxazol/trimetoprim (SMX/TMP) 800/160 mg PO, a cada 24 horas ou três vezes por semana; SMX/TMP 400/80 mg PO, a cada 24 horas. Até à data, nenhum outro fármaco mostrou maior eficácia na profilaxia primária de PPj. ${ }^{47,49}$ Este agente permite também profilaxia eficaz contra Listeria monocytogenes, Toxoplasma gondii e algumas espécies de Nocardia.

A profilaxia primária de PPj deve ser mantida enquanto o fator de risco para a infeção continuar presente. A maioria dos autores preconiza suspensão da profilaxia quando a dose de corticoterapia for inferior a $20 \mathrm{mg} /$ dia de equivalente de prednisolona. ${ }^{42}$ As orientações nas doenças neoplásicas recomendam a sua suspensão seis semanas após o início do desmame da imunossupressão. ${ }^{47}$ Alguns autores sugerem descontinuação da profilaxia apenas se o doente apresentar contagens de CD4 superiores a $200 \mu \mathrm{L}$ durante pelo menos seis meses. ${ }^{50}$

O tratamento de eleição da PPj é também baseado em esquemas com SMX/TMP. A corticoterapia está recomendada em indivíduos com critérios de gravidade.

\section{INFEÇÃO POR LISTERIA}

A listeriose deve-se geralmente à ingestão de alimentos contaminados. Doença neoplásica, transplante de órgão, infeção por VIH ${ }^{51}$ e terapêutica com glucocorticoides, agentes anti-TNF- $\alpha^{52}$ e alemtuzumab são fatores de risco. ${ }^{53}$

A prevenção da listeriose rege-se por recomendações de higiene alimentar, com evicção de carnes malcozinhadas, peixes fumados, alimentos germinados crus e produtos lácteos não pasteurizados. ${ }^{54}$ Indivíduos sob alemtuzumab devem manter estas recomendações nas duas semanas pré-tratamento e durante pelo menos um mês após a última administração. . $33,55-57^{-5}$

O SMX/TMP é eficaz na prevenção da listeriose, sendo utilizado como profilaxia em doentes sob alemtuzumab. ${ }^{53}$

\section{INFEÇÃO POR STRONGYLOIDES STERCORALIS}

A infeção por Strongyloides stercoralis é uma parasitose endémica de regiões tropicais e subtropicais. ${ }^{58} \mathrm{O}$ risco de infeção grave associa-se a estados de imunossupressão, sendo os corticoides os fármacos mais frequentemente implicados. ${ }^{58}$

O rastreio deve ser realizado a todos os doentes que irão ser submetidos a imunossupressão (independentemente do fármaco) e que preencham qualquer um dos seguintes critérios ${ }^{59}$ :

- Sintomas compatíveis com parasitose cutânea ou intestinal;

- Viagem/residência em área endémica e história de contato cutâneo com solo;

- Infeção conhecida por vírus linfotrópico de células T humanas (HTLV) 1 (fator de risco independente para infeção grave);

- Eosinofilia periférica persistente de etiologia não esclarecida.

O rastreio é realizado através de serologia e/ou pesquisa de larvas nas fezes em três amostras (se presença de sintomas).

Perante um rastreio positivo, o tratamento ou erradicação deve ser realizado com ivermectina: no caso de infeção passada ou subclínica (serologia positiva em doente assintomático), na dose de $200 \mu \mathrm{g} / \mathrm{kg} /$ dia durante dois dias consecutivos; se infeção ativa sintomática, na dose de 200 $\mu \mathrm{g} / \mathrm{kg} /$ dia durante dois dias consecutivos, podendo repetir-se em duas semanas por forma a completar um ciclo de autoinfeção do parasita.

\section{INFEÇÕES URINÁRIAS DE REPETIÇÃO}

$\mathrm{Na}$ esclerose múltipla (EM), existe risco acrescido de infeções do trato urinário (ITU) recidivantes, que se associa não só ao uso de fármacos imunossupressores, mas também às características da doença, que cursa frequentemente com disfunções da motilidade vesical com necessidade frequente de cateterização urinária para controlo dos sintomas. ${ }^{60}$ Não há orientações concretas de abordagem destes casos, pelo que o clínico deve reforçar as medidas preventivas a adotar e proceder prontamente ao diagnóstico e tratamento destas infeções. 
Os sintomas habitualmente associados a ITU podem estar ausentes ou ser confundidos com os sintomas de disfunção vesical, devendo considerar-se esse diagnóstico perante sintomas mais inespecíficos: desconforto lombar ou abdominal, anorexia, letargia, incontinência entre cateterizações urinárias ou alteração da cor ou odor da urina. ${ }^{60}$

Perante suspeita de ITU e alteração no sedimento urinário, deve ser colhida urocultura.$^{60}$ Nos doentes sob algaliação intermitente ou de longa duração, só está indicado colher urina para análise microbiológica na presença de sintomas neurológicos ou urinários de novo. ${ }^{60}$

O tratamento de bacteriúria assintomática não está recomendado por rotina nos doentes com EM ${ }^{60}$ e deve apenas ser considerado na presença de surto da doença com planeamento de utilização de corticoides endovenosos (EV). ${ }^{61,62} \mathrm{Na}$ presença de ITU sintomática, deve realizar-se tratamento empírico com antimicrobianos de espectro mais largo do que na população geral, com base no padrão de suscetibilidade local e isolamentos microbiológicos prévios, dirigindo-se a antibioterapia de acordo com o teste de suscetibilidade aos antimicrobianos (TSA) assim que possível. ${ }^{60}$ Considera-se adequado um curso de cinco a sete dias (alargado até 14 dias em caso de sépsis). ${ }^{60,61}$

A gestão das ITU recorrentes (mais de três episódios nos últimos 12 meses ou mais de dois episódios em seis meses) deve ser feita em consulta específica de Urologia para abordagem dos sintomas e fatores de risco (hipo/hiperreatividade vesical, litíase, etc.), ${ }^{60,61}$ não estando indicado por rotina o uso de profilaxia antibiótica. . $^{62,63}$

Embora sem evidência robusta que demonstre diminuição do risco de ITU, as estratégias comportamentais preventivas devem ser reforçadas, incluindo esvaziamento vesical frequente, higiene adequada pós-micção e defecação, hidratação abundante e micção pós-coital. ${ }^{62,63}$ Também não

\section{REFERÊNCIAS}

1. Fernández-Ruiz $M$, Meije $Y$, Manuel $\mathrm{O}$, Akan $\mathrm{H}$, Carratalà J, Aguado JM, et al. ESCMID Study Group for Infections in Compromised Hosts (ESGICH) Consensus Document on the safety of targeted and biological therapies: an infectious diseases perspective (Introduction). Clin Microbiol Infect. 2018;24:S2-9.

2. Rubin LG, Levin MJ, Ljungman P, Davies EG, Avery R, Tomblyn $M$, et al. 2013 IDSA clinical practice guideline for vaccination of the immunocompromised host. Clin Infect Dis. 2014;58:309-18.

3. Visser LG. The immunosuppressed traveler. Infect Dis Clin North Am. 2012;26:609-24.

4. Farez MF, Correale J, Armstrong MJ, Rae-Grant A, Gloss D, Donley $D$, et al. Practice guideline update summary: vaccine-preventable infections and immunization in multiple sclerosis: Report of the Guideline Development, Dissemination, and Implementation Subcommittee of the American Academy of Neurology. Neurology. 2019;93:584-94.

5. Direção-Geral da Saúde. Programa Nacional de Vacinação. Lisboa: DGS; 2020.

6. American College of Rheumatology. COVID-19 vaccine clinical guidance summary for patients with rheumatic and musculoskeletal diseases. 2021. [consultado 2021 abr 10]. Disponível em: https://www. rheumatology.org/Portals/0/Files/COVID-19-Vaccine-Clinical-GuidanceRheumatic-Diseases-Summary.pdf.

7. Direção-Geral da Saúde. Norma 002/2021 de 30/01/2021 atualizada a 10/03/2021: Campanha de Vacinação Contra a COVID-19. Lisboa: DGS; 2021.

8. Cantini F, Nannini C, Niccoli L, Petrone L, Ippolito G, Goletti D. Risk of existem estudos consistentes que demonstrem vantagem da utilização de compostos naturais, como o extrato de arando vermelho ou os lisados bacterianos, na prevenção de infeções urinárias em doentes com EM; contudo, na ausência de contraindicações, o seu uso pode ser considerado. ${ }^{60,62,63}$

\section{CONCLUSÃO}

A gestão do risco de infeção no indivíduo imunossuprimido constitui um desafio clínico. Na estruturação da estratégia preventiva, são fundamentais a caracterização da patologia que motiva a imunossupressão (terapêuticas atuais e passadas, seguimento, intercorrências, envolvimento da doença, grau de atividade), a compreensão do mecanismo de ação do imunossupressor, a aferição de infeções prévias, o reconhecimento de fatores de risco (caracterização epidemiológica, atividade profissional, história de viagens, conviventes), a realização de rastreios laboratoriais, a administração de vacinas, a educação do doente e a monitorização de sintomas e sinais clínicos, na dependência de uma gestão clínica necessariamente individualizada. Atendendo a que a evidência científica sobre este tema, quando disponível, se encontra dispersa, o estabelecimento ou revisão de recomendações de abordagem clínica poderá contribuir para o aperfeiçoamento da prestação de cuidados médicos.

\section{CONFLITOS DE INTERESSE}

Os autores declaram não ter qualquer conflito de interesse relativamente ao presente artigo.

\section{FONTES DE FINANCIAMENTO}

Os autores declaram não ter recebido subsídios ou bolsas para a elaboração deste artigo.

tuberculosis reactivation in patients with rheumatoid arthritis, ankylosing spondylitis, and psoriatic arthritis receiving non-anti-TNF-targeted biologics. Mediators Inflamm. 2017;2017:8909834.

9. Dobler CC. Biologic agents and tuberculosis. Microbiol Spectr. 2016;4.

10. Duarte R, Campainha S, Cotter J, Rosa B, Varela P, Correia A, et al. Position paper on tuberculosis screening in patients with immune mediated inflammatory diseases candidates for biological therapy. Acta Reumatol Port. 2012;37:253-9.

11. Sellam J, Hamdi H, Roy C, Baron G, Lemann M, Puéchal X, et al. Comparison of in vitro-specific blood tests with tuberculin skin test for diagnosis of latent tuberculosis before anti-TNF therapy. Ann Rheum Dis. 2007;66:1610-5.

12. Direção-Geral da Saúde. Manual de Tuberculose e Micobactérias Não Tuberculosas. Lisboa: DGS; 2020.

13. Duarte R, Villar M, Carvalho A. Tratamento da tuberculose de infecção latente. As recomendações actuais. Rev Port Pneumol. 2010;16:80914.

14. Hasan T, Au E, Chen S, Tong A, Wong G. Screening and prevention for latent tuberculosis in immunosuppressed patients at risk for tuberculosis: a systematic review of clinical practice guidelines. BMJ Open. 2018;8:e022445.

15. British Thoracic Society Standards of Care Committee. BTS recommendations for assessing risk and for managing Mycobacterium tuberculosis infection and disease in patients due to start anti-TNFalpha treatment. Thorax. 2005;60:800-5.

16. Loomba R, Liang TJ. Hepatitis $B$ reactivation associated with immune 
suppressive and biological modifier therapies: current concepts, management strategies, and future directions. Gastroenterology. 2017; 152:1297-309.

17. European Association for the Study of the Liver. EASL 2017 Clinical practice guidelines on the management of hepatitis $B$ virus infection. $J$ Hepatol. 2017;67:370-98.

18. Perrillo RP, Gish R, Falck-Ytter YT. American Gastroenterological Association Institute technical review on prevention and treatment of hepatitis $\mathrm{B}$ virus reactivation during immunosuppressive drug therapy. Gastroenterology. 2015;148:221-44.e3.

19. Di Bisceglie AM, Lok AS, Martin P, Terrault N, Perrillo RP, Hoofnagle $\mathrm{JH}$. Recent US Food and Drug Administration warnings on hepatitis $B$ reactivation with immune-suppressing and anticancer drugs: just the tip of the iceberg? Hepatology. 2015;6:703-11.

20. Terrault NA, Lok AS, McMahon BJ, Chang KM, Hwang JP, Jonas MM, et al. Update on prevention, diagnosis, and treatment of chronic hepatitis B: AASLD 2018 hepatitis B guidance. Hepatology. 2018;67:1560-99.

21. Kartau M, Sipilä JO, Auvinen E, Palomäki M, Verkkoniemi-Ahola A. Progressive multifocal leukoencephalopathy: current insights. Degener Neurol Neuromuscul Dis. 2019;9:109-21.

22. Kaplan JE, Benson C, Holmes KK, Brooks JT, Pau A, Masur H. Guidelines for prevention and treatment of opportunistic infections in HIV-infected adults and adolescents: recommendations from CDC the National Institutes of Health, and the HIV Medicine Association of the Infectious Diseases Society of America. MMWR Recomm Rep. 2009;58:1-207; quiz CE1-4.

23. Mateen FJ, Muralidharan R, Carone M, van de Beek D, Harrison DM, Aksamit AJ, et al. Progressive multifocal leukoencephalopathy in transplant recipients. Ann Neurol. 2011;70:305-22.

24. Hadjadj J, Guffroy A, Delavaud C, Taieb G, Meyts I, Fresard A et al. Progressive multifocal leukoencephalopathy in primary immunodeficiencies. J Clin Immunol. 2019;39: 55-64.

25. Epstein DJ, Dunn J, Deresinski S. Infectious complications of multiple sclerosis therapies: implications for screening, prophylaxis, and management. Open Forum Infect Dis. 2018;5:ofy174.

26. Redelman-Sidi G, Michielin O, Cervera C, Ribi C, Aguado JM, Fernández-Ruiz M, et al. ESCMID Study Group for Infections in Compromised Hosts (ESGICH) consensus document on the safety of targeted and biological therapies: an infectious diseases perspective (Immune checkpoint inhibitors, cell adhesion inhibitors, sphingosine1-phosphate receptor modulators and proteasome inhibitors). Clin Microbiol Infect. 2018;24:S95-107.

27. Salmon-Ceron D, Tubach F, Lortholary O, Chosidow O, Bretagne S, Nicolas $\mathrm{N}$, et al. Drug-specific risk of non-tuberculosis opportunistic infections in patients receiving anti-TNF therapy reported to the 3-year prospective French RATIO registry. Ann Rheum Dis. 2011;70:616-23.

28. Brownlee WJ, Chataway J. Opportunistic infections after alemtuzumab: new cases of norcardial infection and cytomegalovirus syndrome. Mult Scler. 2017;23:876-7.

29. Borhan WM, Dababo MA, Thompson LD, Saleem M, Pashley N. Acute necrotizing herpetic tonsillitis: a report of two cases. Head Neck Pathol. 2015;9:119-22.

30. Fine AJ, Sorbello A, Kortepeter C, Scarazzini L. Central nervous system herpes simplex and varicella zoster virus infections in natalizumabtreated patients.Clin Infect Dis. 2013;57:849-52.

31. Food and Drug Administration. Lemtrada ${ }^{\circledR}$ (alemtuzumab): Full Prescribing Information. 2017. [consultado 2020 jun 4]. Disponivel em: https://www.accessdata.fda.gov/drugsatfda_docs/ label/2017/103948s5158lbl.pdf.

32. Lyon CC, Thompson D. Herpes zoster encephalomyelitis associated with low dose methotrexate for rheumatoid arthritis. J Rheumatol. 1997;24:589-91.

33. Kinder A, Stephens S, Mortimer N, Sheldon P. Severe herpes zoster after infliximab infusion. Postgrad Med J 2004;80:26.

34. Yawn BP, Saddier P, Wollan PC, St Sauver JL, Kurland MJ, Sy LS. A population-based study of the incidence and complication rates of herpes zoster before zoster vaccine introduction. Mayo Clin Proc. 2007;82:1341-9.

35. McLean-Tooke A, Aldridge C, Waugh S, Spickett GP, Kay L. Methotrexate, rheumatoid arthritis and infection risk: what is the evidence? Rheumatology. 2009;48:867-71.

36. Kanda Y, Mineishi S, Saito T, Saito A, Yamada S, Ohnishi M, et al. Long-term low-dose acyclovir against varicella-zoster virus reactivation after allogeneic hematopoietic stem cell transplantation. Bone Marrow Transplant. 2001;28:689-92.

37. Food and Drug Administration. Mavenclad® (cladribine): full prescribing information. 2019. [consultado 2020 maio 28]. Disponível em: https:// www.accessdata.fda.gov/drugsatfda_docs/label/2019/022561s000lbl. pdf.

38. Martin-Garrido I, Carmona EM, Specks U, Limper AH. Pneumocystis pneumonia in patients treated with rituximab. Chest. 2013;144:258-65.

39. Fillatre P, Decaux O, Jouneau S, Revest M, Gacouin A, Robert-Gangneux $\mathrm{F}$, et al. Incidence of Pneumocystis jiroveci pneumonia among groups at risk in HIV-negative patients. Am J Med. 2014;127:1242.e11-7.

40. Roux A, Gonzalez F, Roux M, Mehrad M, Menotti J, Zahar JR, et al. Update on pulmonary Pneumocystis jirovecii infection in non-HIV patients. Med Mal Infect. 2014;44:185-98.

41. Youssef J, Novosad SA, Winthrop KL. Infection risk and safety of corticosteroid use. Rheum Dis Clin North Am. 2016;42:157-76, ix-X.

42. Wolfe RM, Peacock JE Jr. Pneumocystis pneumonia and the rheumatologist: which patients are at risk and how can PCP be prevented? Curr Rheumatol Rep. 2017;19:35.

43. Long MD, Farraye FA, Okafor PN, Martin C, Sandler RS, Kappelman MD. Increased risk of pneumocystis jiroveci pneumonia among patients with inflammatory bowel disease. Inflamm Bowel Dis. 2013;19:1018-24.

44. Stern A, Green H, Paul M, Vidal L, Leibovici L. Prophylaxis for Pneumocystis pneumonia (PCP) in non-HIV immunocompromised patients. Cochrane Database Syst Rev. 2014;10:CD005590.

45. European AIDS Clinical Society. Guidelines version 10.0. Brussels: EACS; 2019.

46. Stiehm ER OH, Winkelstein JA. Immunodeficiency disorders general considerations. In: Stiehm ER OH, Winkelstein JA, editors. Immunological disorders in infants and children. $5^{\text {th }}$ ed. Philadephia: Elsevier Saunders; 2004: 289.

47. Cooley L, Dendle C, Wolf J, Teh BW, Chen SC, Boutlis C, et al Consensus guidelines for diagnosis, prophylaxis and management of Pneumocystis jirovecii pneumonia in patients with haematological and solid malignancies, 2014. Intern Med J. 2014;44:1350-63.

48. Chatelanat O, Van Delden C, Adler D, Guerne PA, Nendaz M, Serratrice J. Facteurs de risque et prophylaxie de la pneumonie à Pneumocystis jirovecii chez les patients non VIH. Rev Med Suisse. 2018;14:1829-33.

49. Park JW, Curtis JR, Moon J, Song YW, Kim S, Lee EB. Prophylactic effect of trimethoprim-sulfamethoxazole for pneumocystis pneumonia in patients with rheumatic diseases exposed to prolonged high-dose glucocorticoids. Ann Rheum Dis. 2018;77:644-9.

50. Suryaprasad A, Stone JH. When is it safe to stop Pneumocystis jiroveci pneumonia prophylaxis? Insights from three cases complicating autoimmune diseases. Arthritis Rheum. 2008;59:1034-9.

51. Schuchat A, Deaver KA, Wenger JD, Plikaytis BD, Mascola L, Pinner $\mathrm{RW}$, et al. Role of foods in sporadic listeriosis. I. Case-control study of dietary risk factors. The Listeria Study Group. JAMA. 1992;267:2041-5.

52. Slifman NR, Gershon SK, Lee JH, Edwards ET, Braun MM. Listeria monocytogenes infection as a complication of treatment with tumor necrosis factor alpha-neutralizing agents. Arthritis Rheum. 2003;48:31924.

53. Mazzitelli M, Barone S, Greco G, Serapide F, Valentino P, Giancotti A, et al. Listeria infection after treatment with alemtuzumab: a case report and literature review. Would antibiotic prophylaxis be considered? Infez Med. 2020;28:258-62

54. Centers for Disease Control and Prevention. Listeria (Listeriosis). 2019 [consultado 2020 jun 05]. Disponível em: https://www.cdc.gov/listeria/ prevention.html.

55. Wray S, Havrdova E, Snydman DR, Arnold DL, Cohen JA, Coles AJ, et al. Infection risk with alemtuzumab decreases over time: pooled analysis of 6-year data from the CAMMS223, CARE-MS I, and CARE-MS II studies and the CAMMS03409 extension study. Mult Scler. 2019;25:1605-17.

56. Meca-Lallana JE, Fernández-Prada M, García Vázquez E, Moreno Guillén S, Otero Romero S, Rus Hidalgo M, et al. Consensus statement on the use of alemtuzumab in daily clinical practice in Spain. Neurologia. 2020 (in press). doi: 10.1016/j.nrl.2019.11.003.

57. Rau D, Lang M, Harth A, Naumann M, Weber F, Tumani $H$, et al. Listeria meningitis complicating alemtuzumab treatment in multiple sclerosisreport of two cases. Int J Mol Sci. 2015;16:14669-76.

58. Krolewiecki A, Nutman TB. Strongyloidiasis: a neglected tropica disease. Infect Dis Clin North Am. 2019;33:135-51.

59. Keiser PB, Nutman TB. Strongyloides stercoralis in the immunocompromised population. Clin Microbiol Rev. 2004;17:208-17.

60. Phé V, Pakzad M, Curtis C, Porter B, Haslam C, Chataway J, et al Urinary tract infections in multiple sclerosis. Mult Scler. 2016;22:855-61.

61. Royal College of Physicians. National Clinical Guideline C. National Institute for Health and Clinical Excellence: Guidance. Urinary incontinence in neurological disease: management of lower urinary tract 
dysfunction in neurological disease. London: RCP; 2012

62. European Association of Urology. The European Association of Urology (EAU) Urological Infections Guidelines. Arnhem: EAU; 2020.

63. Sihra N, Goodman A, Zakri R, Sahai A, Malde S. Nonantibiotic prevention and management of recurrent urinary tract infection. Nat Rev Urol. 2018;15:750-76.

64. Furer V, Rondaan C, Heijstek MW, Agmon-Levin N, van Assen S, Bijl $\mathrm{M}$, et al. 2019 update of EULAR recommendations for vaccination in adult patients with autoimmune inflammatory rheumatic diseases. Ann Rheum Dis. 2020;79:39-52.

65. McLean HQ, Fiebelkorn AP, Temte JL, Wallace GS. Prevention of measles, rubella, congenital rubella syndrome, and mumps, 2013: summary recommendations of the Advisory Committee on Immunization Practices (ACIP). MMWR Recomm Rep. 2013;62:1-34

66. Gilli K, Remberger M, Hjelmqvist H, Ringden O, Mattsson J. Sequential organ failure assessment predicts the outcome of SCT recipients admitted to intensive care unit. Bone Marrow Transplant. 2010;45:6828.

67. Centers for Disease Control and Prevention. Use of 13-valent pneumococcal conjugate vaccine and 23-valent pneumococcal polysaccharide vaccine for adults with immunocompromising conditions: recommendations of the Advisory Committee on Immunization Practices (ACIP). MMWR Morb Mortal Wkly Rep. 2012;61:816-9.

68. Hammitt LL, Bulkow LR, Singleton RJ, Nuorti JP, Hummel KB, Miernyk KM, et al. Repeat revaccination with 23-valent pneumococcal polysaccharide vaccine among adults aged 55-74 years living in Alaska: no evidence of hyporesponsiveness. Vaccine. 2011;29: 2287-95.

69. Direção-Geral da Saúde. Norma 011/2015 de 23/06/2015: Vacinação contra infeções por Streptococcus pneumoniae de grupos com risco acrescido para doença invasiva pneumocócica (DIP). Lisboa: DGS; 2015.
70. Muhammad RD, Oza-Frank R, Zell E, Link-Gelles R, Narayan KM, Schaffner W, et al. Epidemiology of invasive pneumococcal disease among high-risk adults since the introduction of pneumococcal conjugate vaccine for children. Clin Infect Dis. 2013;56:e59-67.

71. Schillie S, Vellozzi C, Reingold A, Harris A, Haber P, Ward JW, et al. Prevention of hepatitis B virus infection in the United States: recommendations of the Advisory Committee on Immunization Practices. MMWR Recomm Rep. 2018;67:1-31.

72. Jin $H$, Tan Z, Zhang X, Wang B, Zhao Y, Liu P. Comparison of accelerated and standard hepatitis $B$ vaccination schedules in high-risk healthy adults: a meta-analysis of randomized controlled trials. PLoS One. 2015;10:e0133464.

73. Nelson NP, Weng MK, Hofmeister MG, Moore KL, Doshani M, Kamili $\mathrm{S}$, et al. Prevention of hepatitis A virus infection in the United States: recommendations of the Advisory Committee on Immunization Practices, 2020. MMWR Morb Mortal Wkly Rep. 2020;69:1-38.

74. Mbaeyi SA, Bozio CH, Duffy J, Rubin LG, Hariri S, Stephens DS, et al. Meningococcal vaccination: recommendations of the Advisory Committee on Immunization Practices, United States, 2020. MMWR Recomm Rep. 2020;69.

75. Kallinowski B, Jilg W, Buchholz L, Stremmel W, Engler S. Immunogenicity of an accelerated vaccination regime with a combined hepatitis a/b vaccine in patients with chronic hepatitis C. Z Gastroenterol. 2003;41:983-90.

76. Garland SM, Brotherton JM, Moscicki AB, Kaufmann AM, Stanley $\mathrm{M}$, Bhatla N, et al. HPV vaccination of immunocompromised hosts. Papillomavirus Res. 2017;4:35-8.

77. Mary A Albrecht MJ. Vaccination for the prevention of shingles (herpes zoster). Waltham: UpToDate; 2020 [consultado 2020 jun 05]. Disponível em: https://www.uptodate.com/contents/vaccination-for-the-preventionof-shingles-herpes-zoster. 